Article

\title{
Evaluation and Classification of Rural Multifunction at a Grid Scale: A Case Study of Miyun District, Beijing
}

\author{
Ziyan Yin ${ }^{1,2,3}$, Yu Liu ${ }^{2,3, *}$ and Yuchun Pan ${ }^{2,3}$ \\ 1 School of Land Science and Technology, China University of Geosciences (Beijing), Beijing 100083, China; \\ yinzy@cugb.edu.cn \\ 2 Beijing Research Center for Information Technology in Agriculture, Beijing Academy of Agriculture and \\ Forestry Sciences, Beijing 100097, China; panyc@nercita.org.cn \\ 3 National Engineering Research Center for Information Technology in Agriculture, Beijing 100097, China \\ * Correspondence: liuyu@nercita.org.cn; Tel.: +86-010-51503627
}

Citation: Yin, Z.; Liu, Y.; Pan, Y.

Evaluation and Classification of Rural Multifunction at a Grid Scale: A Case Study of Miyun District, Beijing. Sustainability 2021, 13, 6362. https:// doi.org/10.3390/su13116362

Academic Editor: Anastasios Michailidis

Received: 11 April 2021

Accepted: 31 May 2021

Published: 3 June 2021

Publisher's Note: MDPI stays neutral with regard to jurisdictional claims in published maps and institutional affiliations.

Copyright: (c) 2021 by the authors. Licensee MDPI, Basel, Switzerland. This article is an open access article distributed under the terms and conditions of the Creative Commons Attribution (CC BY) license (https:/ / creativecommons.org/licenses/by/ $4.0 /)$.

\begin{abstract}
Rural areas are a natural, economic and social complex with multiple functions. Identifying rural multifunction scientifically is the basis for promoting efficient rural spatial planning and sustainable development strategy. In this paper, we calculated and characterized the rural productionliving-ecological (PLE) functions at a grid scale of $300 \times 300 \mathrm{~m}$ in Miyun District by establishing an evaluation index system. Several types of rural functional area were identified with the help of an ISO cluster unsupervised classification tool. Three main results were found as follows. (1) The values of the production, living, ecological functions and multifunction ranged from 0-0.101, 0-0.204, 0.009-0.241 and 0.009-0.302, respectively. Ecological function was dominant in this area. (2) The overall spatial patterns of production and living functions showed the characteristic of being "high in the south and low in the north", and areas with high values were almost distributed around urban areas and the Miyun Reservoir. While for the ecological function and multifunction, they possessed the opposite characteristics to production and living functions, with high values concentrated in the mountainous areas in the northwest, northeast, east and south of Miyun District. (3) According to the clustering results, rural multifunction of Miyun District was divided into four types: ecological conservation, employment and residence, recreation and potential development, with the area proportions of $44.22 \%, 17.92 \%, 20.73 \%$ and $17.13 \%$, respectively. Each functional type showed a characteristic of agglomeration. In the future, the study of rural multifunction at micro scales should be paid more attention to better understand the functional differences within the country. This research can provide a decision-making reference for demarcation of rural production-livingecological space and compilation of spatial planning.
\end{abstract}

Keywords: rural multifunction; grid scale; classification; production-living-ecological spaces; Miyun District

\section{Introduction}

Rural areas are a special regional complex with natural, social and economic characteristics, certain structures and functions, which are different from those of urban areas [1]. During rapid urbanization and industrialization, most countries and regions in the world have experienced the stages of rural hollowing out and the widening gap between urban and rural areas [2,3]. The economic status of agriculture has declined, the rural service sector has sprung up, and the movement of urban and rural populations have accelerated, leading to the reconstructing of social and economic structures [4]. Furthermore, intensified resource scarcity and environmental degradation have also occurred during the rapid urbanizing [3]. Rural decline is a global issue and has inevitably been accentuated through increasing global levels of urban development [5].

The processes of urbanization and industrialization were completed earlier in developed countries, and thus, the transformation of rural structures and functions also occurred 
earlier. From the 1980s-1990s, in western US, migration patterns, technological developments, and altered human-land relationships led to tremendous changes in rural land use patterns and conflicts between "newcomers" and "old-timers" [6]. Holmes argued that the rural multifunctional transition in Australia could be characterized as a shift from the dominant production goals to a variable mix of production, consumption and protection [7]. Similar transitions of rural economic, social and environmental structures also occurred in UK and New Zealand [8,9]. For developing countries, they underwent these rural changes later than developed countries, however, the forms were similar. Since the late 1980s, rural multifunction in Poland has changed from agriculture as the leading industry to a mix of industrial, tourist and recreational, and residential functions, etc. [10]. Since the 21st century, the rapid urbanization, industrialization, informatization and agricultural modernization in China has also led to the expansion of traditional rural functions and brought about problems such as non-agriculturalization, non-grain preference, abandonment of farmland use and idle rural housing land, etc. [11,12]. In short, social development has brought about functional transitions in rural area, and has also caused some negative effects on its structures and environment. In rural areas, key problems during the process of rural reconstruction include, the optimization and adjustment of production, and living and ecological spatial structures [13].

The concept of production, living and ecological (PLE) spaces, which was first proposed at the 18th National Congress of the Communist Party of China in 2012, required an intensive and efficient production space, livable and moderate living space, and clean and beautiful ecological space [14]. Since this proposal, relevant contents have been put forward in many Chinese documents and policies. Territorial spatial planning and village planning both clearly put forward the scientific layout of the rural PLE spaces, which was also a necessity for building a beautiful country and realizing a green and sustainable rural development. In November 2020, the Proposal on Formulating the 14th Five-Year Plan for National Economic and Social Development and the Long-range Goals of 2035 further emphasized that "the development should be based on the carrying capacity of resources and the environment, and give full play to the comparative advantages of different regions, forming the three spatial patterns of urban, agricultural production and ecological functional areas, gradually." In this context, research on the evaluation and classification of rural PLE functions can help to grasp the characteristics of rural spatial structure and promote the sustainable development of rural areas.

Identification of PLE functions is the basis for the demarcation of PLE spaces and the study of functional transitions, as well as an important research focus for rural geography. Space is a complex geographic entity under the influence of various factors, such as, nature, economy, society and human beings. The same area may have dominant, secondary or combined functions [15], and therefore the evaluation of PLE spaces' functions can integrate various elements into the planning system. Although the concept of a PLE spaces is rarely used internationally [16], scholars have still conducted much work about the evaluation and zoning of regional multifunction. Logical evaluation and zoning have helped to realize the maximum value of spatial functions and meet social needs $[17,18]$. To quantify different rural functions, indicators were usually selected from land use, employment, industry, geographical locations, policy and other aspects. Rural functional types were divided into residence, services, production, tourism and protection, etc. [19-21]. The scale of evaluation covered nation, region, landscape and farms [22-24], and research was conducted using methods such as, scenario analysis, index value, and multi-criteria evaluation $[10,25,26]$. Chinese scholars mainly used an index value method to calculate rural functions, which involved agricultural production, ecological conversation, social welfare guarantee and other functions $[27,28]$, using the administrative boundaries as evaluation units, such as county (district), town and village [29-31]. Large-scale evaluation units have limited reference significance for rural spatial planning, and it is difficult to reflect the specific distribution characteristics of each function within the village. In addition, in the selection and calculation methods of indicators, previous studies only took administrative units 
as the boundary and ignored the spatial characteristics of some indicators with spatial coverage. Therefore, it is an important direction for rural geography to construct the evaluation index system from the perspective of PLE spaces and explore the method of microscale-oriented evaluation and classification of rural PLE functions.

With the proposal of rural revitalization and the needs for social development, rural areas have increasingly attracted interest in recent years. In fact, rural management and planning projects can be put forward scientifically on the condition of a full understanding of rural structures and functions. Hence, our work attempts to establish an evaluation index system of rural PLE functions at a grid scale in Miyun District in order to promote the microscale evaluation of rural multifunction. We also reveal the spatial distribution characteristics of functions and identify different types of multifunction. The objective of this paper is to provide reference for the demarcation of rural PLE spaces and territorial spatial planning, as well as to provide basic support for the study of rural functional changes and the guidance for rural development. The paper is organized as follows: Section 2 introduces the concepts of rural multifunction, territorial spatial planning and PLE spaces. Section 3 introduces the materials and methods, and also describes the definition and calculation methods of the index system. Section 4 shows the results, including the brief analysis of index calculation, the spatial distribution characteristics and classification of multifunction. Section 5 are the policy implications and discussions based on the above analysis, and the main conclusions of this study are summarized in Section 6.

\section{Theoretical Framework}

\subsection{Rural Multifunction}

The concept of rural multifunction originated from agricultural multifunction and land use multifunction. In 1992, "multifunctionality" was introduced by the United Nations at the World Earth Summit on "Environment and development" in Rio de Janeiro, Brazil. One year later, the term "multifunctional agriculture" was firstly officially used by the European Council for Agricultural Law [32]. In 2001, the concept of "land use multifunctionality" was proposed by the Sixth Framework of the European Union. Afterwards, this concept was extended to rural area.

Rural multifunction refers to the beneficial effects of rural areas on the development of nature and human beings by exerting its own attributes and acting together with other systems, including the guarantee of its own needs, the support for the urban system and the cooperation with other rural systems [33]. In this paper, rural multifunction is divided into production, living and ecological functions, which are also three primary elements that constitute the rural area. Production function represents the ability of a country to provide its residents with products and services, and develop the economy. Living function is the ability of a country to provide living environment and living security for its residents. Ecological function shows how a country can cope with external disturbance, regulate itself and maintain ecosystem stability [29,34].

\subsection{Territorial Spatial Planning and PLE Spaces}

In May 2019, the publishing of the Opinions on Establishing and Supervising the Implementation of the Territorial Spatial Planning (hereinafter referred to as "the Opinions") marked the basic formation of the top-level design of the territorial spatial planning [35]. As a comprehensive program, it integrates multiple plans into a whole, such as economic and social development planning, urban planning, land use planning and ecological environment planning, etc. In essence, territorial spatial planning can be understood as the comprehensive optimization of territorial spatial patterns, and the advanced deployment and arrangement of land utilization, policy coordination and government management [36].

The optimization of PLE spaces is a core task of China's territorial spatial planning [36]. The Opinions put forward that "Taking factors such as population distribution, economic layout, land use and environmental protection into account, we will make a scientific layout of production, living and ecological space." Obviously, territorial spatial planning is 
made on the basis of territorial spatial background conditions and the demarcation of PLE spaces can reflect background conditions well.

\section{Materials and Methods}

\subsection{Study Area}

Miyun District lies in the northeast of Beijing, at the junction of Yanshan Mountains and North China Plain, locating from $40^{\circ} 13^{\prime} 7^{\prime \prime} \mathrm{N}-40^{\circ} 47^{\prime} 57^{\prime \prime} \mathrm{N}$ and $116^{\circ} 39^{\prime} 33^{\prime \prime} \mathrm{E}-$ $117^{\circ} 30^{\prime} 25^{\prime \prime} \mathrm{E}$ (Figure 1). The district is surrounded by mountains in the east, north and west and its total area is $2229.45 \mathrm{~km}^{2}$, with mountainous area accounting for $79.5 \%$. In 2018 , the Gross Domestic Product (GDP) of Miyun District was 30.02 billion CNY, accounting for $0.99 \%$ of the total GDP of Beijing, and ranking 13th among 16 districts. The shares of primary, secondary and tertiary industry in GDP were $4.4 \%, 39.1 \%$ and $56.5 \%$, respectively (those of Beijing were $0.4 \%, 18.6 \%$ and $81.0 \%$, respectively), indicating that agricultural and industrial production take a great proportion in Miyun District. By the end of 2018, the registered population was $438,000,55.7 \%$ of which were engaged in agricultural production. Due to the restriction of topography, economic development is backward in this area, the income level of villagers is lower than that of downtown Beijing, and rural development is unbalanced and inadequate [37]. It would be effective to promote rural leisure industry in this district to revitalize the countryside [38], since tourism resources are abundant in mountainous areas, providing a beautiful environment and various recreation places, such as Yunmengshan National Forest Park, Taoyuan Fairy Valley and Beijing WTown. Miyun District is an important ecological protection and water conservation area of Beijing, as well as a sensitive area for the integrated urban and rural development. The implementation of rural revitalization strategy brings both opportunities and challenges to regional development. It is vital for Miyun District to protect the environment and take ecological security as the top priority; however, sustainable development of economy and society and coordinated layout of PLE spaces should be pushed synchronously. Therefore, it is of immense significance to evaluate and classify rural multifunction in this area.

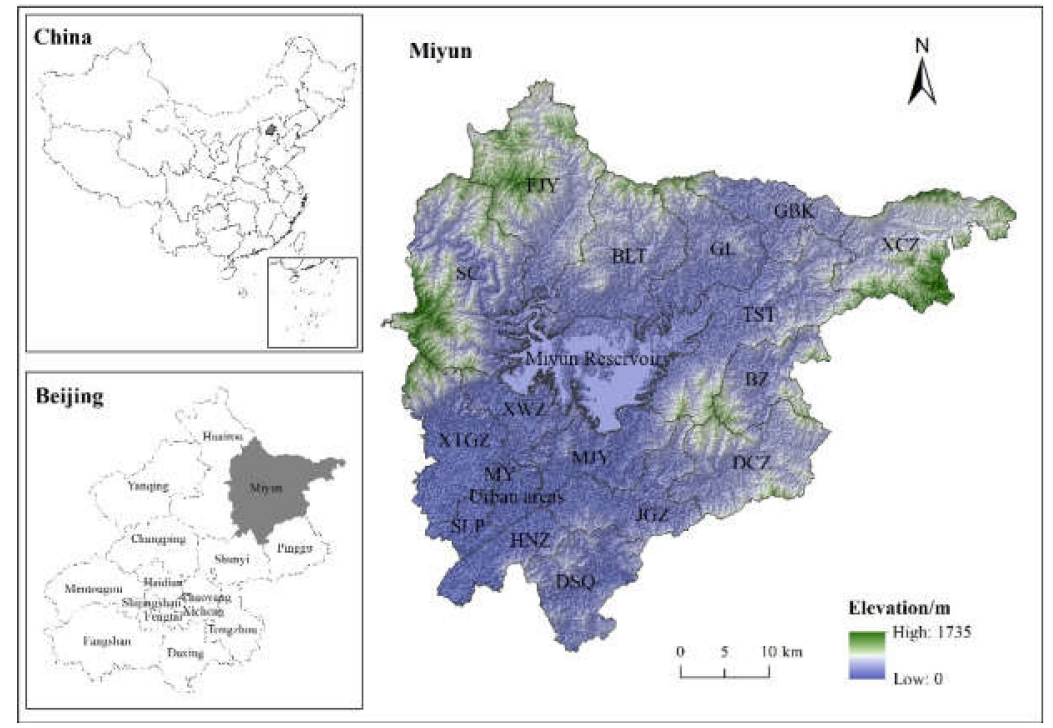

Figure 1. Study Area (MY, SLP, HNZ, DSQ, JGZ, MJY, XWZ, XTGZ, DCZ, BZ, TST, XCZ, GBK, GL, BLT, FJY and SC are the abbreviation of the township names of Miyun, Shilipu, Henanzhai, Dongshaoqu, Jugezhuang, Mujiayu, Xiwengzhuang, Xitiangezhuang, Dachengzi, Beizhuang, Taishitun, Xinchengzi, Gubeikou, Gaolin, Bulaotun, Fengjiayu and Shicheng).

\subsection{Data Sources and Methodology}

\subsubsection{Data Sources}

The evaluation and classification of rural multifunction in Miyun District was studied on the basis of statistical data and spatial data in 2018. The socioeconomic data were ob- 
tained from Statistical Yearbook of Miyun District. The distribution of enterprises, medical institutions and schools were derived from Point of Interest (POI) data, which were captured and provided from the Amap API interface by a specialized corporation. The data of land use and administrative boundaries were obtained through the interpretation of remote sensing images. The Normalized Difference Vegetation Index (NDVI) was calculated from Landsat 8 OLI_TRIS satellite image (http:/ / www.gscloud.cn/ (the date is 8 April 2018)). The statistical and spatial data took the village and space as the unit, respectively. We first delimited the administrative boundaries and grids based on land use data, and then built the connection between the statistical/spatial data and the evaluation unit.

\subsubsection{Delimitation of Evaluation Units}

A moderate evaluation unit is the basis for spatial evaluation of rural multifunction. If the evaluation unit is too large, it is difficult to reflect the spatial distribution characteristics of multifunction; if the evaluation unit is too small, it will lose the value of some functions and the significance of rural multifunction [39]. Considering the size of spots of land use map in Miyun District, a $300 \times 300 \mathrm{~m}$ grid was selected as the evaluation unit [39-42]. Due to the high degree of urbanization in Tanying, Gulou and Guoyuan Street (divided as urban areas) and little residential land in the Miyun Reservoir, these two areas were excluded in our study. The study area was totally divided into 31,895 grid units of $300 \times 300 \mathrm{~m}$, using the Create Fishnet Tool in ArcGIS 10.5.

\subsubsection{Index System}

The delimitation of rural PLE spaces is an important part of the territorial spatial planning system [43], and also the key to rural agricultural production, economic development and ecological protection. Based on the availability of data at a grid level evaluation unit and the decomposition of socioeconomic data, 12 indicators were selected to establish the evaluation index system of rural PLE functions according to previous studies (Table 1) $[30,37,40,44,45]$.

Table 1. Evaluation index system for rural PLE functions.

\begin{tabular}{|c|c|c|c|c|}
\hline Criteria & First Level Indicators & Basic Level Indicator & Calculation Method & Weight \\
\hline \multirow{4}{*}{ Production function } & \multirow{2}{*}{ Agricultural production } & Grain output(P1) & Grain output per grid & 0.088 \\
\hline & & Fruit output(P2) & Fruit output per grid & 0.061 \\
\hline & \multirow{2}{*}{$\begin{array}{l}\text { Non-agricultural } \\
\text { production }\end{array}$} & Enterprise aggregation(P3) & $\begin{array}{l}\text { Aggregation of enterprises in secondary } \\
\text { and tertiary industries }\end{array}$ & 0.094 \\
\hline & & Density of traffic land(P4) & Traffic land area/grid area & 0.057 \\
\hline \multirow{4}{*}{ Living function } & \multirow{2}{*}{ Basic living } & Villagers' income(L1) & Villagers' income per grid & 0.100 \\
\hline & & Density of rural settlements(L2) & Rural settlements area/grid area & 0.095 \\
\hline & \multirow{2}{*}{ Welfare guarantee } & $\begin{array}{l}\text { Coverage of medical } \\
\text { institutions(L3) }\end{array}$ & $\begin{array}{l}\text { Coverage of medical institutions such as } \\
\text { hospitals, health centers and clinics }\end{array}$ & 0.054 \\
\hline & & $\begin{array}{l}\text { Coverage of primary and } \\
\text { secondary education(L4) }\end{array}$ & $\begin{array}{l}\text { Coverage of primary and } \\
\text { secondary schools }\end{array}$ & 0.051 \\
\hline \multirow{4}{*}{ Ecological function } & \multirow{2}{*}{ Ecological conservation } & Forest coverage rate(E1) & Forest area/grid area & 0.121 \\
\hline & & NDVI(E2) & Normalized difference vegetation index & 0.056 \\
\hline & \multirow[t]{2}{*}{ Ecological maintenance } & $\begin{array}{l}\text { Water and wetland } \\
\text { coverage rate(E3) }\end{array}$ & Water and wetland area/grid area & 0.156 \\
\hline & & $B R I(\mathrm{E} 4)$ & Biological richness index & 0.067 \\
\hline
\end{tabular}

The main difference between the indicators selected in this paper and those in other studies is that we have considered the characteristic of spatial coverage of some indicators, such as enterprise aggregation (P3), coverage of medical institutions (L3) and coverage of primary and secondary education (L4). Previously, the numbers of enterprises, schools and hospital beds were used in the functional evaluation at the scales of administrative 
units $[30,40]$, which are not suitable at the grid scale. Moreover, enterprises, schools and hospitals have a certain scope of influence, that is, they serve more than just people in a single administrative unit.

\subsubsection{Indicator Calculation Methods}

Production function includes agricultural/non-agricultural production functions. Agricultural production function reflects the ability to provide agricultural products such as grain, oil, fruits, vegetables and meat, mainly related to the primary industry. Here, grain output (P1) and fruit output (P2) were selected to calculate agricultural production function. The two indicators were counted in the statistical yearbook with village as a unit. We decomposed P1/P2 into the grid according to the proportion of cultivated/garden land area in the grid to the cultivated/garden land area in the village. Non-agricultural production function depicts the rural economic development capacity except agriculture, represented by enterprise aggregation (P3) and density of traffic land (P4). P3 reflects the concentration of production factors within a certain range. The POI data of the secondary and tertiary industries in Miyun District were analyzed by kernel density, whose index was divided into 9 grades from low to high, with 1 to 9 points, respectively. P4 reflects the development level of rural transportation.

Living function includes basic living/welfare guarantee functions. Basic living function represents the ability to provide basic living conditions, which is mainly related to housing and income. Villages' income (L1) and density of rural settlements (L2) were selected to quantify this function. The range of rural settlements is composed of towns and villages in the land use status classification. Assuming that the population is evenly distributed in the settlements, the total income of a village was decomposed into the grid according to the proportion of settlements area in the grid to the settlements area in the village. Welfare guarantee function is the ability to provide convenience and benefits for residents and guarantee people's livelihood, which is represented by coverage of medical institutions (L3) and primary and secondary education (L4). L3 and L4 were calculated by establishing buffers. Medical institutions were divided into secondary medical institutions (secondary hospitals), primary medical institutions (health service centers), and others (clinics), according to their different scope of service and social security meaning. The influencing radius of secondary medical institutions is $3000 \mathrm{~m}$, and the influencing radius of primary and other medical institutions is $1500 \mathrm{~m}$ [46]. Firstly, a number of buffer zones were established and 3, 2 and 1 points were assigned to secondary, primary and other medical institutions, respectively, and the function value was then calculated. Secondary and primary schools were divided into city key, district key and ordinary schools according to the differences in social function and educational levels, with 3 points, 2 points and 1 point, respectively. The influencing radii of urban middle/primary schools, rural middle/primary schools are 1000, 500, 3000 and $2000 \mathrm{~m}$, respectively [47].

Ecological function includes ecological conservation function and ecological maintenance function. Ecological conservation function is the ability to protect the ecosystem from pollution and disturbance, represented by forest coverage rate (E1) and NDVI (Normalized Difference Vegetation Index) (E2). Ecological maintenance function depicts the ability to protect biodiversity, purify water and soil and ensure sustainable development of the region. Water and wetland coverage (E3) and BRI (Biological Richness Index) (E4) were selected to calculate this function. The formula for NDVI and BRI are shown below.

$$
N D V I=\frac{N I R-R}{N I R+R}
$$

where NIR is the reflectance of the near infrared band; $R$ is the reflectance of infrared band.

$$
B R I=A_{b i o}\left(0.35 \cdot S_{f}+0.21 \cdot S_{g}+0.28 \cdot S_{w}+0.11 \cdot S_{c}+0.04 \cdot S_{c o n}+0.01 \cdot S_{u}\right) / S
$$


where $A_{b i o}$ is the normalized coefficient, with a reference value of 511.264; $S_{f}, S_{g}, S_{w}, S_{c}, S_{c o n}$ and $S_{u}$ are the area of forest, grassland, water, cultivated land, construction land, unused land, respectively; $S$ represents the sum area.

The indicators selected in this paper are all positive, that is, they have positive effects on rural functions. In order to eliminate the influence of different magnitude and measurement, the maximum difference normalization method was adopted, and the formula is shown as follows:

$$
x^{\prime}{ }_{i j}=\frac{x_{i j}-x_{\min }}{x_{\max }-x_{\min }}
$$

where $x_{i j}$ is the original value of an indicator; $x_{i j}^{\prime}$ is the normalized value; $x_{\max }$ and $x_{\min }$ represent the maximum and minimum values of an indicator, respectively.

\subsubsection{Weight Method}

The subjective weight method mixes the subjective factors of the evaluator, which is insufficient to reflect the scientific grounding and fairness of the evaluation mechanism [48]. The objective weight method is determined by mathematical method, which takes little account of the condition of the evaluation area. Therefore, the two weight methods were combined to reduce the error. First, the production, living and ecological functions were given $0.3,0.3$ and 0.4 weights, respectively, considering the important ecological function orientation of Miyun District. Then, entropy weight method (EWM) and analytic hierarchy process (AHP) were used to calculate the weight of each index. The final weight was determined by taking the average value. Finally, the weighted summation method was used to calculate the index of rural production, living, ecological functions and multifunction. The visual analysis was carried out in ArcGIS 10.5 .

\subsubsection{Classification of Rural Multifunction}

According to the evaluation results of PLE functions, rural multifunction of Miyun District was divided into several types. In this research, ISO clustering unsupervised classification tool in ArcGIS 10.5 was used to carry out the classification of rural multifunction [41]. Similar evaluation units were divided into the same type. This tool combines the functions of ISO clustering and maximum likelihood classification, and is relatively simple and quick to realize the automatic classification of raster data. The number of categories is greater than or equal to 2 . If the input band is multi-band raster data, the composite bands tool is used to create a new raster data set composed of these specific bands, and then the new raster data set is classified.

\section{Results}

\subsection{Analysis of Index Calculation Results}

The calculation results of the 12 indicators were standardized into $[0,1]$ according to Equation (3), and their spatial distribution characteristics were shown in Figure 2.

As seen in Figure 2, in general, Miyun District produced more grain and fruit in the south than in the north. P1 was higher in the south and northwest of HNZ, the northeast of DSQ, the west of SLP and the south of XTGZ. P2 was higher in the northeast of DSQ, the northeast of MJY, the southwest of BLT and the north of XCZ. Enterprise aggregated obviously around urban areas, that is, a large number of enterprises gathered in the northeast of SLP and the southeast of MJY. P4 presented a distribution characteristic of "banding". Areas with high traffic density were located in HNZ, JGZ, DCZ and TST, etc., where the national highway G45 passes.

For indicators representing the living function, L1-L4 all exhibited the characteristics of high values distributing around urban areas. Specifically, people living in MY, SLP, HNZ, MJY, JGZ, XWZ and XTGZ earned more money, had more residential land, and achieved better medical treatment and education than people in other areas of Miyun District. In addition, the 4 indicators were also high near the north and northeast of the Miyun Reservoir, such as the south of BLT, the south of GL and the west of TST. 
From E1, we could note the forest distributed more in the mountainous areas in the northwest, northeast, east and south of Miyun District, including SC, FJY, BLT, XCZ and DSQ, etc. The distribution of E2 was fragmented, which was relatively higher in $\mathrm{XWZ}$, HNZ and DSQ. E3 showed a zoning distribution, consistent with the distribution of Chao River, Bai River and Chaobai River. Areas with high values of E3 were mainly located in the interior of SLP and SC, the junction of JGZ and MY, and the junction of GL and TST. The distribution pattern of E4 was similar to that of E1, since the species richness of forest is the highest among all land types. Thus, SC, FJY, BLT, XCZ and DSQ were richer with regard to species.

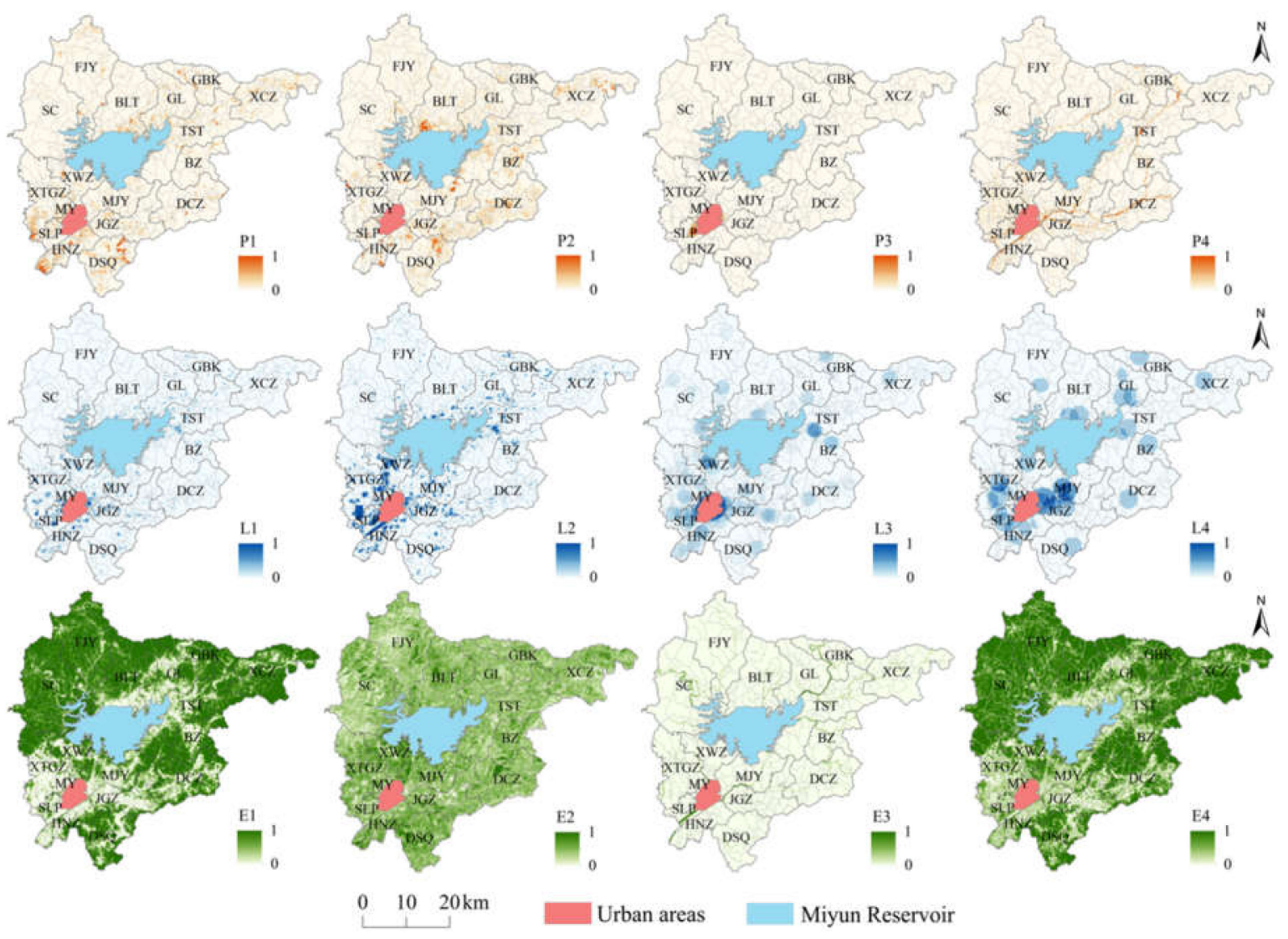

Figure 2. Distribution patterns of 12 evaluation index.

\subsection{Characteristics of Rural PLE Functions and Multifunction}

From Table 2, we can see that the index of production, living, ecological functions and multifunction in Miyun District ranged from 0-0.101, 0-0.201, 0.009-0.241 and 0.009-0.302, respectively. Compared with the living and ecological functions, the production function in Miyun District was relatively weak. The average values of PLE functions and multifunction were $0.002,0.012,0.190$ and 0.203 , respectively, further indicating that the ecological function played a dominant role in this area.

Table 2. The minimum, average and maximum values of each function.

\begin{tabular}{cccc}
\hline & Minimum Value & Average Value & Maximum Value \\
\hline Production function & 0 & 0.002 & 0.101 \\
Living function & 0 & 0.012 & 0.204 \\
Ecological function & 0.009 & 0.190 & 0.241 \\
Multifunction & 0.009 & 0.203 & 0.302 \\
\hline
\end{tabular}


According to Figure 3, the spatial patterns of PLE functions and multifunction in Miyun District all presented a characteristic of agglomeration. The distribution patterns of production and living functions were similar, with an overall characteristic of "high in the south and low in the north". Areas with high values were mainly located around urban areas and the Miyun Reservoir. Towns surrounding urban areas, such as MY, SLP, HNZ, JGZ, MJY and XTGZ were main areas for production in Miyun District due to the flat terrain, developed transportation, concentrated industry and superior geographical conditions. Industrial agglomeration had provided a large number of employment opportunities for villagers, leading to the high population density, income level and proportion of residential land. High-quality medical and educational resources and excellent public service facilities also concentrated in these areas, leading to the strong production and living functions around urban areas. For those areas located around the Miyun Reservoir, such as the south of BLT, the south of GL, the west of TST and the north of XWZ, they had the advantages of abundant water resource and humid climate, providing them with the large farmland and residential land. Therefore, these places were suitable for living and agricultural production. Areas around the Miyun Reservoir also had relatively excellent medical and educational resources, giving rise to the strong living function. In addition, because of the high proportion of cultivated/garden/residential land in the northwest of DSQ and the north of $\mathrm{XCZ}$, and the traffic arteries running through $\mathrm{DCZ}$ and $\mathrm{BZ}$, the production and living functions in these areas were strong. However, the production and living functions in FJY, SC and other mountainous areas were weak, due to the restrictions of topography and traffic.

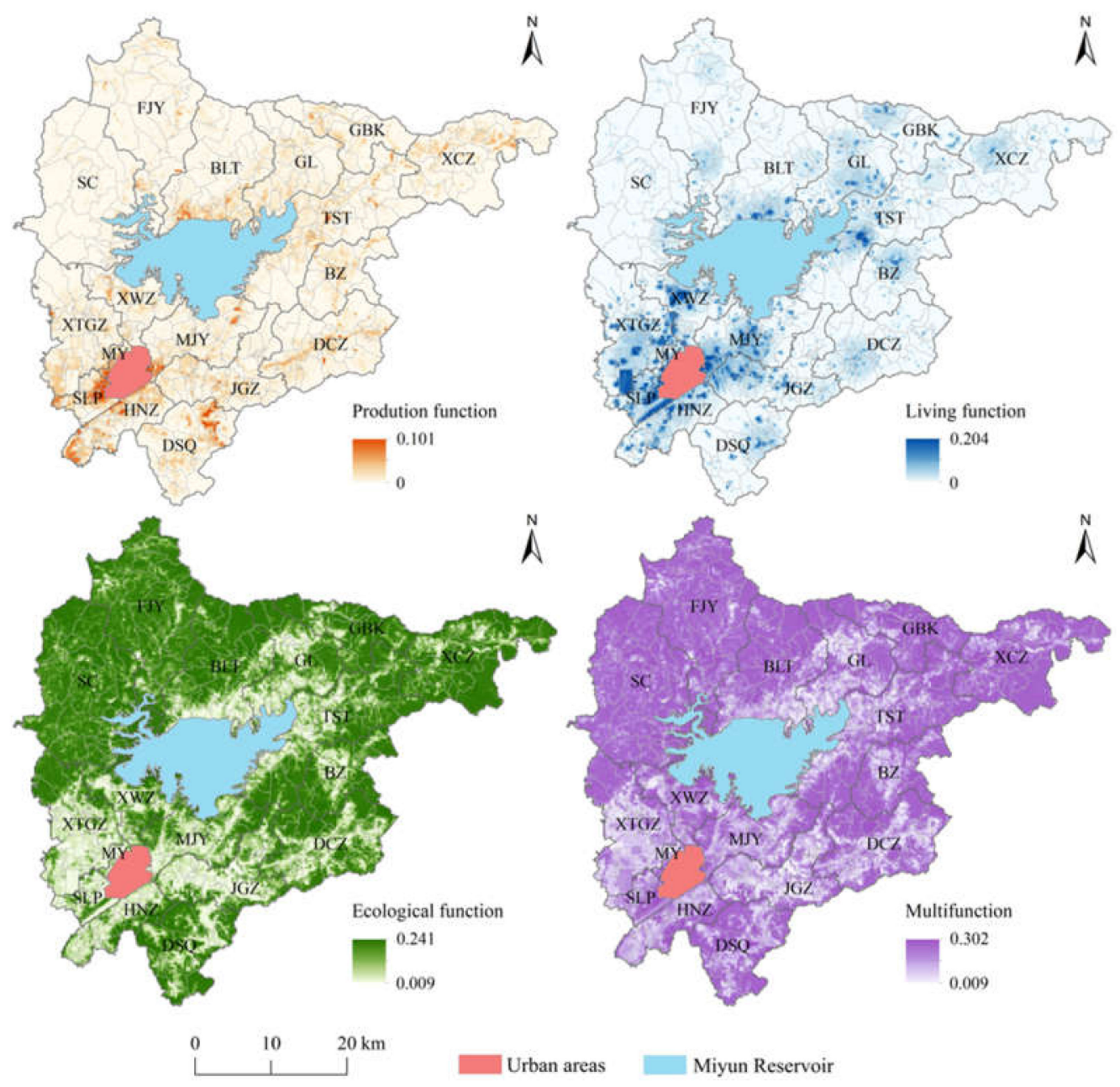

Figure 3. Distribution patterns of PLE functions and multifunction in Miyun District. 
As for ecological function and multifunction, they possessed the opposite characteristics to production and living functions, with high values concentrated in the mountainous areas in the northwest, northeast, east and south of Miyun District. A significant negative correlation could be observed between the ecological function and production/living functions, that is, areas with strong production and living functions usually had a weak ecological function (Figure 4). Areas with a strong ecological function were mainly distributed in SC, FJY, BLT, XCZ, GBK, DSQ, with a small part in GL, TST, BZ, DCZ, XWZ and XTGZ. The northwest of Miyun District consisted of many forest parks and natural scenic spots, such as Yunmengshan National Forest Park, Five-Building Forest Park, Yunlong Mountain, Taoyuan Fairy Valley and Black Longtan Scenic Spot, where the forest and vegetation coverage rates were high and species were rich. As a result, these areas had strong ecological conversation and maintenance function and became an important water and ecological conversation zone of Beijing. Besides, a large number of forest parks, natural reserves and scenic spots could be found in the northeast, east and south of Miyun District, such as Beijing WTown, Yunxiu Valley, Jinshanling Great Wall and White Longtan Scenic Spot, etc. Areas with a variety of natural tourism resources had higher forest and water coverage and better environment, hence, the ecological function there was strong.

The spatial distribution characteristic of multifunction was similar to that of E1, E4 and the ecological function, resulting from the orientation of "ecological conservation zone", with the forest area accounting for $64.80 \%$ of the total area. Areas with high values were mainly distributed in SC, FJY, BLT, GBK, XCZ, TST, BZ, DCZ and DSQ. These areas undertook the responsibility of maintaining regional ecological stability and water conservation, and constituted an important ecological protection barrier of the capital. Towns around urban areas, including MY, SLP, MJY and HNZ, were main areas for people's living and employment, and had strong production and living functions, so as to the multifunction. In addition, XWZ had strong production and living functions in the south and strong ecological function in the northeast and south, leading to its strong multifunction.

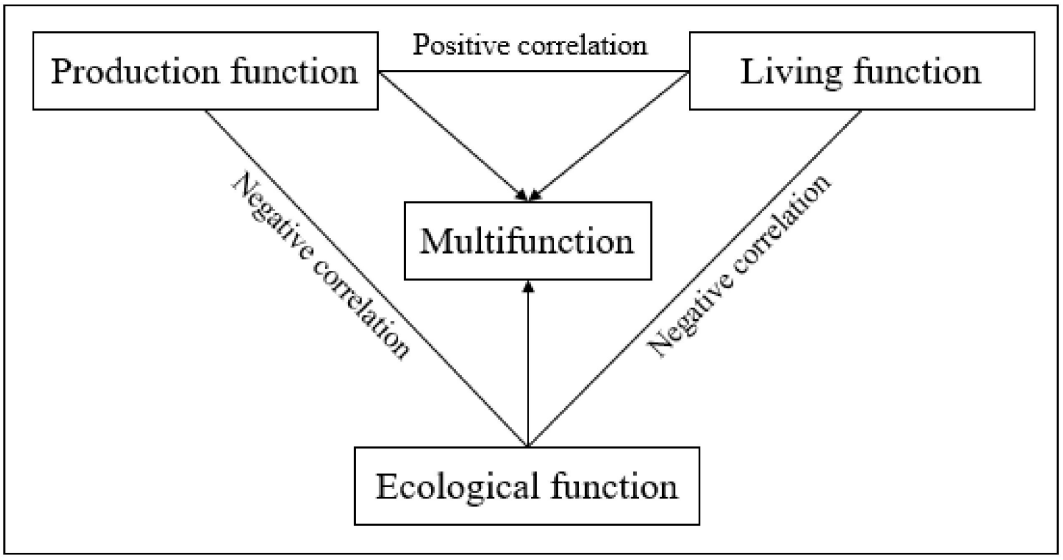

Figure 4. Relationship between PLE functions and multifunction.

\subsection{Classification of Rural Multifunction}

Rural multifunction of Miyun District was divided into four types: ecological conservation, employment and residence, recreation and potential development, according to ISO clustering unsupervised classification (Figure 5). The four types of functional area were described as follows. (1) Ecological conservation type was mainly distributed in mountainous areas in the northwest, northeast, east and south of Miyun District, including some areas of FJY, SC, BLT, XCZ, GBK, TST, BZ, DCZ and DSQ. This type of functional area concentrated most of the forest parks, natural reserves and scenic spots, and was the largest functional area, which accounted for $44.22 \%$ of the total. With a high coverage of forest and vegetation, rich species and ecotourism resources, and beautiful environment, this area became an important ecological barrier, water conservation zone and recreation area of Beijing. (2) Employment and residence type was mainly distributed in the suburbs 
around urban areas and near the north, northeast and southwest of the Miyun Reservoir, including some areas of MY, SLP, XTGZ, XWZ, HNZ, MJY, JGZ, BLT, GL and TST, which accounted for $17.92 \%$ of the total area and showed an obvious characteristic of agglomeration. MY, SLP, HNZ, JGZ, MJY and XTGZ were close to urban areas of Miyun District and downtown Beijing, with complex transportation network, numerous enterprises and great medical and educational conditions. The south of BLT, the south of GL, the west of TST, the north of XWZ, the northeast of DSQ, the center of DCZ and the northwest of BZ were mainly agricultural production and living functional area, where cultivated land and garden land occupied a large proportion. (3) Recreation type was mainly distributed in mountainous areas in the northeast, northwest, east and south of Miyun District, scattered within the ecological conservation type and at the junction of ecological conservation type and potential development type, including some areas of FJY, SC, BLT, GL, GBK, XCZ, TST and DSQ, which accounted for $20.73 \%$ of the total area. The beautiful environment and convenient traffic made these areas suitable for leisure and tourism. (4) Potential development type was mainly distributed in the outer suburbs around urban areas and near the north and northeast of the Miyun Reservoir, and in the outer edge of the employment and residence functional area, including some areas of XTGZ, XWZ, JGZ, MJY, DCZ, BLT, GL, TST and XCZ, accounting for $17.13 \%$ of the total area. Relying on an ideal traffic network, this functional area connected the traffic of towns in Miyun District and between Miyun District and others districts. Additionally, this area was close to employment and residence functional area, indicating the great potential of development.

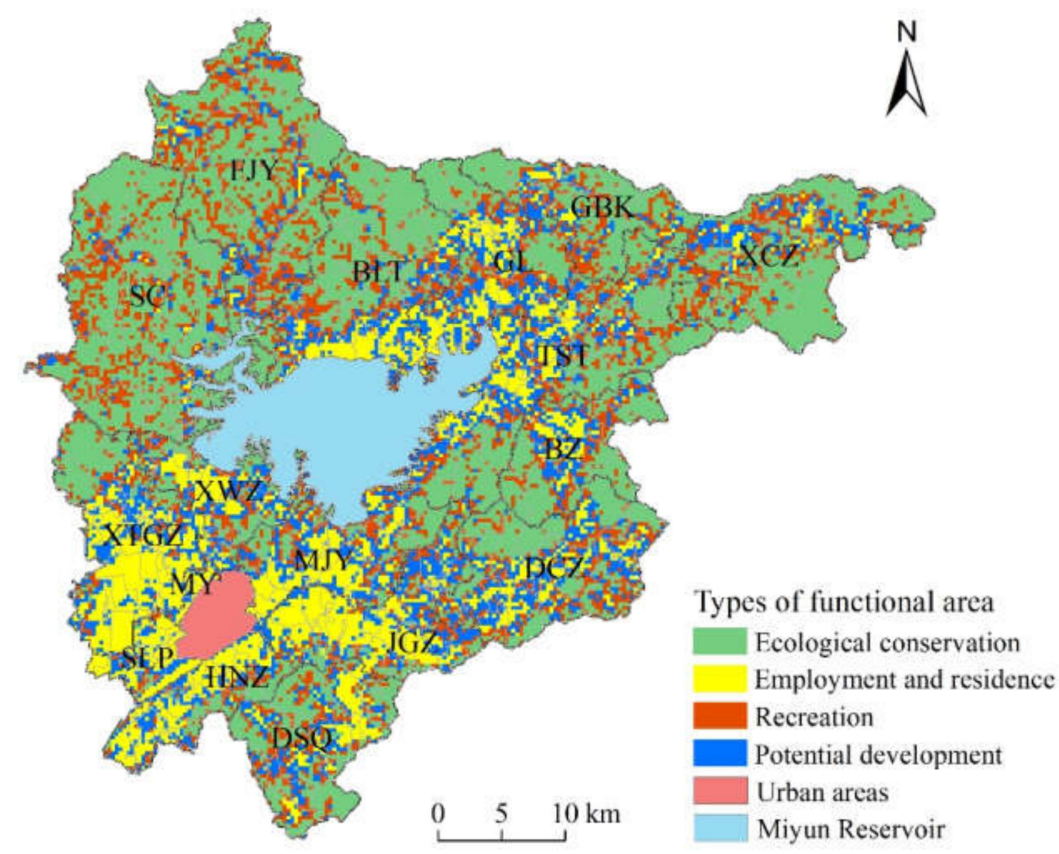

Figure 5. Types of functional area in Miyun District.

\section{Discussion}

Rural multifunction is classified on the basis of the territory and refers to the multiple functions that rural areas perform based on an integral conception of their potential [49]. With the development of society and economy and the change of the urban-rural relationship, rural functions are constantly changing, from the traditional agricultural production to the comprehensive expression of production, living, leisure and ecological conservation, etc. $[7,10]$ Due to the complexity of rural territory, the same area may have one or more of the PLE functions. The formation process of multifunction is not the accumulation of single functions, but the integrated result of the trade-offs or synergies of different functions. Therefore, in order to achieve the maximum value of multifunction and regional 
sustainable development, it is effective to promote the coordinated relationship between PLE functions [50].

This paper attempts to establish an evaluation index system at a grid scale to perfect the functional evaluation at micro scales. The results show the differentiated characteristics of rural PLE functions and multifunction clearly at the micro-scale. Previous evaluation based on administrative units could hardly reflect the specific features of multifunction within the evaluation unit $[29,51]$, however, multifunction varies within a township or village, as is shown in Figure 3. From Table 2, we can note that both the average and maximum values of ecological function index in Miyun District are higher than those of production and living function index, indicating the ecological function is the dominant function in this district. While, in the Beijing-Tianjin-Hebei (BTH) region, production and living functions are stronger than the ecological function [30], showing that rural multifunction is influenced by geographical, economic and social conditions, and has a scaling effect. Moreover, the results also demonstrate that there is a certain relationship of interaction among PLE functions. Production function is positively correlated with the living function, and negatively correlated with the ecological function, which is in line with G.R. and C.W.'s research $[27,52]$. Terrain, geographical location and economic level are the main factors leading to functional differentiation. The interactions between different functions and the causes of functional differentiation are of great importance to learn the formation mechanism of rural multifunction. In terms of the classification of functional areas, different research has different combinations of functions, such as residence, services, agricultural production, tourism, ecological conservation and health regimen, etc. [19-21,53-55] In this paper, functional areas are divided into four types: ecological conservation, employment and residence, recreation and potential development, based on the evaluation results of PLE functions and natural, economic and social conditions in Miyun District.

The evaluation results of rural PLE functions can provide reference for the demarcation of rural PLE spaces, for instance, areas with strong production, living and ecological functions are demarcated as production, living and ecological space, respectively. Multifunctional evaluation is an integrated framework that combines economy, society, environment and human activities. Therefore, the results can well reflect the spatial characteristics of regional structures and provide support for the construction of a modern approach for the territorial spatial planning. In addition, the identification and zoning of rural multifunction is the basis of studying the evolution and driving mechanism of rural structures and functions. A clear understanding of rural structures and functions and their transitions is of great significance for the optimization of rural spatial structures and the promotion of rural sustainable development.

The results of evaluation and classification of rural multifunction present significant spatial differentiation in Miyun District. In this context, different planning and developing policies should be formulated according to different types of functional area. Here are several policy implications. (1) It is important for the ecological conservation type to strengthen the protection of the environment, control the development and utilization of land, and strictly prohibit destruction of water and mountain. Tourism resources are a valuable asset for Miyun District. It is of significance to coordinate these natural landscape resources, improve the quality and value of public tourism space, and provide ecological products, to realize the slogan "lucid waters and lush mountains are invaluable assets" [56]. (2) It is suggested for employment and residence type around urban areas to formulate territorial spatial planning scientifically, which could help to guide the reasonable industrial layout, vacate inefficient industrial and storage land and increase the efficiency of land use. Moreover, the government-subsidized housing system should be improved to adjust and optimize the layout of residential land and promote the balanced relationship between housing and employment. Facilities like schools, hospitals, libraries and gymnasiums also need to be improved. For employment and residence type near the northwest and southwest of the Miyun Reservoir, it is necessary to protect both the quality and quantity of cultivated land, control the use of pesticides and fertilizers, and strengthen the protection 
and restoration of agricultural ecology. Household garbage and sewage need to be treated properly to prevent the pollution of reservoirs and rivers. Medical and basic educational conditions are also suggested to be improved in rural areas, and infrastructure such as water, roads, electricity and gas ought to be equipped according to the demand of the villagers. (3) For recreation type, we should protect the ecology of this functional area and prevent domestic garbage and sewage from polluting the environment. The relationship between tourism and ecology must be dealt with properly, so that an environmentallyfriendly tourism habitat can be built in the future. (4) The construction of transportation networks as a potential development type needs to be improved to increase regional connectivity, enhance service capacity, and provide the city with abundant industrial and agricultural products. The government should also guide the rational distribution of industries, strengthen industrial division of labor and cooperation, and encourage the development of agricultural wholesale and logistics industries.

Nevertheless, there is still room for further progress of this research. First, the selection of indicators is mostly based on subjective consideration and literatures. To improve the objectivity, we have considered the characteristics of the study area and excluded some indicators with a linear correlation. The indicators selected in this paper are also widely used in other studies with regard to the evaluation of rural multifunction [30,34,44]. Evaluating the objectivity of the indicators might be an effective way to improve the scientific grounding and persuasion of the evaluation index system. Second, China's territorial spatial planning is formulated on the basis of administrative boundaries. The rural planning and management are almost implemented on the scale of administrative village. The question of how to link the grid scale evaluation results with village-level planning and combine theoretical research with concrete practice still need further exploration. In the future, under the theoretical framework of relationship between human beings and land and urban-rural integration, the interactions between different functions and the cause of functional differentiation will be discussed in depth to better guide the spatial planning and development of rural spaces.

\section{Conclusions}

Taking Miyun District as the study area, this paper established an evaluation index system to quantify the rural PLE functions and multifunction in 2018 at a grid scale of $300 \times 300 \mathrm{~m}$. Then the spatial distribution characteristics of different functions and classification of multifunction were studied with the help of ArcGIS 10.5. The main conclusions were achieved and drawn as follows.

(1) The values of the production, living, ecological functions in Miyun District differed greatly. The average value and maximum value both showed that the functional intensity was ecological > living > production, indicating that the ecological function was dominant in this area. The value of multifunction was determined by the comprehensive action of the three single functions.

(2) The overall spatial patterns of the production and living functions were characterized by the distribution of "high in the south and low in the north", and areas with high values were distributed with moderate density around urban areas and the Miyun Reservoir with developed transportation, concentrated population and superior geographic conditions. In contrast to the spatial distribution characteristics of production and living functions, areas with strong ecological function were mainly distributed in the mountainous areas with high forest coverage in the northwest, northeast, east and south of Miyun District. Rural multifunction was strong in the mountainous areas and around urban areas.

(3) Based on ISO clustering unsupervised classification, the rural multifunction of Miyun District was divided into four types: ecological conservation, employment and residence, recreation and potential development, with the area proportions of $44.22 \%$, $17.92 \%, 20.73 \%$ and $17.13 \%$, respectively. Each type of functional area showed a characteristic of aggregation. The differences in topography, geographical location 
and traffic conditions led to the differentiated formation and distribution of functional areas. In order to realize the sustainable development of each functional area, policies and development strategies should be formulated according to local conditions.

The multifunction of rural area is a comprehensive reflection of natural, social and economic conditions and human activities. The evaluation of rural multifunction at a grid scale is capable of reflecting the distribution characteristics of different functions within rural area accurately and enriched the evaluation system of rural multifunction to a certain extent. The evaluation of rural PLE functions can also provide a decision-making reference for the demarcation of rural PEL spaces, the compilation of territorial spatial planning and sustainable development of rural spaces.

Author Contributions: Conceptualization, Y.L.; methodology, Z.Y.; software, Z.Y.; validation, Y.L.; formal analysis, Z.Y.; investigation, Z.Y.; resources, Y.L.; data curation, Z.Y.; writing-original draft preparation, Z.Y.; writing-review and editing, Z.Y.; visualization, Z.Y.; supervision, Y.P.; project administration, Y.P.; funding acquisition, Y.L. All authors have read and agreed to the published version of the manuscript.

Funding: This research was supported by the National Key R\&D Program of China (2020YFD1100202) and the General Program of Beijing Natural Science Foundation (9192010).

Institutional Review Board Statement: Not applicable.

Informed Consent Statement: Not applicable.

Data Availability Statement: The data presented in this study are available on resonable request from the corresponding author.

Acknowledgments: The authors would like to thank the editors and anonymous reviewers for their detailed and constructive feedback. Ziyan Yin thanks Linnan Tang for the discussion of dealing with data.

Conflicts of Interest: The authors declare no conflict of interest.

\section{References}

1. Liu, Y.; Zhou, Y.; Li, Y. Rural regional system and rural revitalization strategy in China. Acta Geogr. Sin. 2019, 74, 2511-2528.

2. Liu, Y. Research on the geography of rural revitalization in the new era. Geogr. Res. 2019, 38, 461-466.

3. Liu, Y.; Li, Y. Revitalize the world's countryside. Nature 2017, 548, 275-277. [CrossRef]

4. Long, H. Land consolidation and rural spatial restructuring. Acta Geogr. Sin. 2013, 68, 1019-1028.

5. Liu, Y. Introduction to land use and rural sustainability in China. Land Use Policy 2018, 74, 1-4. [CrossRef]

6. Nelson, P.B. Rural restructuring in the American West: Land use, family and class discourses. J. Rural Stud. 2001, 17, 395-407. [CrossRef]

7. Holmes, J. Impulses towards a multifunctional transition in rural Australia: Gaps in the research agenda. J. Rural Stud. 2006, 22, 142-160. [CrossRef]

8. Wilson, O.J. Rural restructuring and agriculture-rural economy linkages: A New Zealand study. J. Rural Stud. 1995, 11, 417-431. [CrossRef]

9. Lobley, M.; Potter, C. Agricultural change and restructuring: Recent evidence from a survey of agricultural households in England. J. Rural Stud. 2004, 20, 499-510. [CrossRef]

10. Bañski, J.; Stola, W. Transformation of the spatial and functional structure of rural areas in Poland. J. Rural Stud. $2002,3,13$.

11. Long, H.; Tu, S.; Ge, D.; Li, T.; Liu, Y. The allocation and management of critical resources in rural China under restructuring: Problems and prospects. J. Rural Stud. 2016, 47, 392-412. [CrossRef]

12. Li, Y.; Long, H.; Liu, Y. Spatio-temporal pattern of China's rural development: A rurality index perspective. J. Rural Stud. 2015, 38, 12-26. [CrossRef]

13. Long, H.; Tu, S. Rural restructuring: Theory, approach and research prospect. Acta Geogr. Sin. 2017, 72, 563-576.

14. Huang, J.; Lin, H.; Qi, X. A literature review on optimization of spatial development pattern based on ecological-production-living space. Prog. Geogr. 2017, 36, 378-391.

15. Li, G.; Fang, C. Quantitative function identification and analysis of urban ecological-production-living spaces. Acta Geogr. Sin. 2016, 71, 49-65.

16. Dong, Z.; Zhang, J.; Si, A.; Tong, Z.; Na, L. Multidimensional analysis of the spatiotemporal variations in ecological, production and living spaces of Inner Mongolia and an identification of driving forces. Sustainability 2020, 12, 7964. [CrossRef] 
17. Wiggering, H.; Dalchow, C.; Glemnitz, M.; Helming, K.; Müller, K.; Schultz, A.; Stachow, U.; Zander, P. Indicators for multifunctional land use-Linking socio-economic requirements with landscape potentials. Ecol. Indic. 2006, 6, 238-249. [CrossRef]

18. King, P.; Annandale, D.; Bailey, J. Integrated economic and environmental planning in Asia: A review of progress and proposals for policy reform. Prog. Plann. 2003, 59, 233-315. [CrossRef]

19. Aizaki, H.; Sato, K.; Osari, H. Contingent valuation approach in measuring the multifunctionality of agriculture and rural areas in Japan. Paddy Water Environ. 2006, 4, 217-222. [CrossRef]

20. Willemen, L.; Hein, L.; Van Mensvoort, M.E.F.; Verburg, P.H. Space for people, plants, and livestock? Quantifying interactions among multiple landscape functions in a Dutch rural region. Ecol. Indic. 2010, 10, 62-73. [CrossRef]

21. Stola, W. An attempt at a functional classification on rural areas in Poland. A methodological approach. Geogr. Pol. 1984, 113-129.

22. Andersen, P.S.; Vejre, H.; Dalgaard, T.; Brandt, J. An indicator-based method for quantifying farm multifunctionality. Ecol. Indic. 2013, 25, 166-179. [CrossRef]

23. Huang, J.; Tichit, M.; Poulot, M.; Darly, S.; Li, S.; Petit, C.; Aubry, C. Comparative review of multifunctionality and ecosystem services in sustainable agriculture. J. Environ. Manag. 2015, 149, 138-147. [CrossRef]

24. Huttunen, S. Revisiting agricultural modernisation: Interconnected farming practices driving rural development at the farm level. J. Rural Stud. 2019, 71, 36-45. [CrossRef]

25. Távora, G.S.G.; Turetta, A.P.D. An approach to map landscape functions in Atlantic Forest-Brazil. Ecol. Indic. 2016, 71, 557-566. [CrossRef]

26. Jeong, J.S.; García-Moruno, L.; Hernández-Blanco, J.; Sánchez-Ríos, A.; Ramírez-Gómez, Á. Identifying priority areas for rural housing development using the participatory multi-criteria and contingent valuation methods in Alange reservoir area, Central Extremadura (Spain). J. Rural Stud. 2017, 50, 117-128. [CrossRef]

27. Wang, C.; Tang, N. Spatio-temporal characteristics and evolution of rural production-living-ecological space function coupling coordination in Chongqing Municipality. Geogr. Res. 2018, 37, 1100-1114.

28. Qu, Y.; Wang, S.; Zhao, L.; Qu, Y.; Wang, S. Spatial pattern and regional regulation of rural territorial multi-functions in Shandong Province, China. Trans. Chin. Soc. Agric. Eng. 2020, 36, 222-232.

29. Gu, X.; Xie, B.; Zhang, Z.; Guo, H.D. Rural multifunction in Shanghai suburbs: Evaluation and spatial characteristics based on villages. Habitat Int. 2019, 92, 102041. [CrossRef]

30. Yang, Y.; Bao, W.; Liu, Y. Coupling coordination analysis of rural production-living-ecological space in the Beijing-Tianjin-Hebei region. Ecol. Indic. 2020, 117, 106512. [CrossRef]

31. Gu, X.; Tao, S.; Lu, F.; Zhou, X. Multi-functional evaluation of metropolitan suburbs and its spatial difference: A case study of 89 towns in Shanghai. J. Nat. Res. 2019, 34, 2281-2290.

32. Wilson, G.A. The spatiality of multifunctional agriculture: A human geography perspective. Geoforum 2009, 40, 269-280. [CrossRef]

33. Liu, Y.; Liu, Y.; Guo, L. Connotations of rural regional multifunction and its policy implications in China. Hum. Geogr. 2011, 26, 103-106.

34. Jiang, G.; Wang, M.; Qu, Y.; Zhou, D.; Ma, W. Towards cultivated land multifunction assessment in China: Applying the "influencing factors-functions-products-demands" integrated framework. Land Use Policy 2020, 99, 104982. [CrossRef]

35. Yang, B.; Chen, P.; Dong, K.; Sun, J. Formation of the national territory development planning system under the background of ecological civilization. Urban Plan. Forum 2019, 16-23. [CrossRef]

36. Yan, J.; Chen, H.; Xia, F. Cognition, direction and path of future spatial planning based on the background of multiple planning integration. China Land Sci. 2017, 31, 21-27.

37. Liu, Y.; Tang, L.; Pan, Y. Multifunctional characteristics and revitalization strategies of different types of rural development at village scale. Trans. Chin. Soc. Agric. Eng. 2019, 35, 9-17.

38. Liu, Y.; Tang, L.; Ren, Y.; Xian, W. Evaluation of rural leisure functions based on multidimensional combination of characteristics in Miyun district of Beijing, China. Mt. Res. 2020, 38, 751-762.

39. Meng, J.; Wang, Q.; Li, F.; Guo, L. Assessing multifunctional land use in the middle reach of the Heihe River basin based on spatial variances. Geogr. Res. 2019, 38, 369-382.

40. Ma, X.; Li, X.; Hu, R.; Khuong, M.H. Delineation of "production-living-ecological" space for urban fringe based on rural multifunction evaluation. Prog. Geogr. 2019, 38, 1382-1392. [CrossRef]

41. Fan, Y.; Jin, X.; Xiang, X.; Yang, X.; Liu, J.; Zhou, Y. Evaluation and spatial characteristics of arable land multifunction in southern Jiangsu. Resour. Sci. 2018, 40, 980-992.

42. Yang, R.; Liu, Y.; Long, H.; Chen, C. Spatial-temporal characteristics of rural residential land use change and spatial directivity identification based on grid in the Bohai Rim in China. Geogr. Res. 2015, 34, 1077-1087.

43. Li, X.; Liu, W.; Xie, Y.; Xu, X.; Dai, J. The delineation and empirical study of production-living-ecological space in village under the background of multiple planning integration. Econ. Geogr. 2019, 39, 146-152.

44. Liu, Y.; Ren, Y.; Pan, Y.; Tang, L. Rural development pattern and zoning for rural revitalization strategy. Trans. Chin. Soc. Agric. Eng. 2019, 35, 281-289.

45. Qu, Y.; Jiang, G.; Zhao, Q.; Ma, W.; Zhang, R.; Yang, Y. Geographic identification, spatial differentiation, and formation mechanism of multifunction of rural settlements: A case study of 804 typical villages in Shandong Province, China. J. Clean. Prod. 2017, 166, 1202-1215. [CrossRef] 
46. Zhang, H. Research on Spatial Layout Optimization of Hierarchical Medical Service Facilities Based on GIS in Xi'an City. Master's Thesis, Northwest University, Xi'an, China, 2019.

47. Guo, M. Resource Allocation and Spatial Layout Efficiency Evaluation of Basic Education in Nanchang City. Master's Thesis, Jiangxi Normal University, Nanchang, China, 2019.

48. Zhang, Y. Study on the Spatial Differentiation and Its Influent Factors of Rural Function-A Case Study of Changsha-ZhuzhouXiangtan Urban Agglomeration. Master's Thesis, Hunan Agricultural University, Changsha, China, 2018.

49. Gomez-Limon, J.A.; Arriaza, M. What does society demand from rural areas? Evidence from southern Spain. N. Medit. 2013, $12,2$.

50. Wang, D.; Jiang, D.; Fu, J.; Lin, G.; Zhang, J. Comprehensive assessment of production-living-ecological space based on the coupling coordination degree model. Sustainability 2020, 12, 2009. [CrossRef]

51. Ma, W.; Jiang, G.; Li, W.; Zhou, T.; Zhang, R. Multifunctionality assessment of the land use system in rural residential areas: Confronting land use supply with rural sustainability demand. J. Environ. Manag. 2019, 231, 73-85. [CrossRef] [PubMed]

52. Ren, G.; Liu, L.; Li, H.; Yuan, C. Evolution on trade-offs and synergy of multifunction of rural landscape in metropolitan suburbs. Trans. Chin. Soc. Agric. Eng. 2019, 35, 273-285.

53. Willemen, L.; Verburg, P.H.; Hein, L.; Van Mensvoort, M.E.F. Spatial characterization of landscape functions. Landsc. Urban Plan. 2008, 88, 34-43. [CrossRef]

54. Bański, J.; Mazur, M. Classification of rural areas in Poland as an instrument of territorial policy. Land Use Policy 2016, 54, 1-17. [CrossRef]

55. Hong, H.; Xie, D.; Guo, L.; Hu, R.; Liao, H. Differentiation of spatial function in a mountainous rural area from a multi-functional perspective. Acta Ecol. Sin. 2017, 37, 2415-2427.

56. Ma, G.; Wang, J.; Yu, F.; Yang, W.; Ning, J.; Peng, F.; Zhou, X.; Zhou, Y.; Cao, D. Framework construction and application of China's Gross Economic-Ecological Product accounting. J. Environ. Manag. 2020, 264, 1-9. [CrossRef] [PubMed] 